$\begin{gathered}\text { International Research Journal of Diabetes and Metabolism } \\ \text { (DOI:10.28933/IRJDM) }\end{gathered}$
(n)

\title{
Frequently oral alterations in diabetic patients
}

\author{
Lima L.F.A1, Santos G.A², Santana J.F³, França L.C4, Ramos L.V.S5, Maia C.S6 \\ 1,2,3,4,5Student Dentistry Course/UFPE; 6Teacher /Researcher Department of Histology and \\ Embryology / UFPE.
}

\begin{abstract}
Introduction: The number of Brazilians diagnosed with diabetes increased by $61.8 \%$ in the last 10 years, from $5.5 \%$ to $8.9 \%$ in 2016. The patient with diabetes has physical possibilities that reduce their immunological capacity, increasing the susceptibility of infections and, among these, countless mouthfuls. Objectives: Identify oral asbestos caused by diabetes and what the mechanisms of the body to occur and / or bypass them. Methodology: A bibliographic review was done in the virtual libraries SCIELO and PubMed, use the articles: Diabetes and Oral diseases. We used criteria for inclusion of published articles from 2013 to 2017, in the Portuguese and English languages, which relate to diabetes, dental and oral ebert. Results: The research resulted in 5,821 articles, of which 22 were separated by presenting a relation with the theme, but only four attendants to the inclusion criteria. Discussion: Diabetes is associated with loss of calcium by the body and may lead to alveolar bone decalcification. As major oral manifestations are known as glossodynia, erythema, xerostomia and taste disorders. Diabetes increases the acidity of the buccal medium, increases viscosity and reduces the flow of salivary, which are risk factors for caries. Periodontal disease, which results in a potent inflammatory response, is a common dental manifestation in poorly controlled diabetics. There are modifications of the microbiota in floating or adherent bacterial plaques at the base of the periodontal pocket, due to the high levels of glucose in the sulcular fluid. As infections lead to inflammation resulting in a stressful situation, which increases tissue resistance to insulin, making it difficult to control diabetes. It was then observed that periodontal therapy reduced the need for insulin administration by the diabetic. Conclusion: It is extremely necessary to know about a pathophysiology of diabetes to relate causes and effects and to adopt a more careful and multidisciplinary dental treatment.

*Correspondence to Author: Lima L.F.A

Student Dentistry Course/UFPE

How to cite this article:

Lima L.F.A, Santos G.A, Santana J.F, França L.C, Ramos L.V.S, Maia C.S. Frequently oral alterations in diabetic patients .International Research Journal of Diabetes and Metabolism, 2018, 1:1

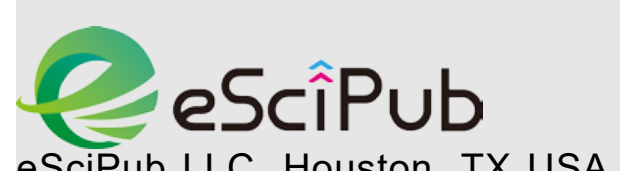
eSciPub LLC, Houston, TX USA. Website: http://escipub.com/
\end{abstract}

Keywords: Oral changes; Diabetes; Dentistry 